\title{
Jaw Device
}

National Cancer Institute

\section{Source}

National Cancer Institute. Jaw Device. NCI Thesaurus. Code C54020.

A device designed to use opposing parts to close on and hold an object. 